\title{
SPECIATION, DISSOLUTION, AND REDOX REACTIONS OF CHROMIUM RELEVANT TO PRETREATMENT AND SEPARATION OF HIGH-LEVEL TANK WASTES
}

\section{EMSP Project 81896}

\author{
Dhanpat Rai ${ }^{1}$, Linfeng $\mathrm{Rao}^{2}$, and Sue B. Clark ${ }^{3}$ \\ ${ }^{1}$ Pacific Northwest National Laboratory, Richland, WA \\ ${ }^{2}$ Lawrence Berkeley National Laboratory, Berkeley, CA \\ ${ }^{3}$ Washington State University, Pullman, WA
}

\section{RESEARCH OBJECTIVES}

Chromium, one of the problematic elements in tank sludges, is considered the most important constituent in defining the total volume of high-level radioactive waste (HLW) glass. Current sludge washing processes (e.g. caustic leaching, $3 \mathrm{M} \mathrm{NaOH}$ ) are not effective in removing $\mathrm{Cr}$. This inefficient removal would result in production of an unacceptably large volume of HLW glass and thus a tremendous increase in the cost of waste disposal. This proposed research seeks to develop fundamental data for chromium (Cr) reactions that are not currently available but are essential for developing effective methodologies for removing $\mathrm{Cr}$ form high-level waste (HLW). Our objectives are to study 1) the dissolution of several solid phases (e.g., $\mathrm{CrOOH}, \mathrm{Cr}_{2} \mathrm{O}_{3}(\mathrm{c}), \mathrm{Cr}(\mathrm{OH})_{3}$, and $\mathrm{Fe}$ and $\mathrm{Cr}$, binary hydroxides, identified to be important from sludge leaching studies) in highly alkaline solutions and in the presence of other ele ctrolytes (e.g., carbonate, phosphate, sulfate, nitrite), and 2) the effect of the nature of $\mathrm{Cr}$ solid phases and aqueous species on their redox reactivity with a variety of potential oxidants (e.g., $\mathrm{H}_{2} \mathrm{O}_{2}$, persulfate, $\mathrm{O}_{2}$, and ferrate). This information will provide critical support for developing enhanced pretreatment strategies for removing $\mathrm{Cr}$ from HLW and will achieve a major cost reduction in HLW disposal.

Thermodynamic and kinetic data concerning the behavior of $\mathrm{Cr}$ in multi-component, highly non-ideal electrolyte systems is being obtained. A model describing such behavior is being developed based on these fundamental data, tested with actual HLW tank sludge washing, and incorporated into the Environmental Simulations Program (ESP) model for use by Hanford, Savannah River, and other U. S. Department of Energy (DOE) site personnel for predicting the efficacy of enhanced pretreatment strategies for the removal of Cr from HLW. 


\section{RESEARCH PROGRESS AND IMPLICATIONS}

Prior to the research performed under our current EMSP project, fundamental information was unavailable on the solubility, speciation, or redox reactivity of $\mathrm{Cr}(\mathrm{III})$ in tank-like environments. Consequently, the behavior of $\mathrm{Cr}$, including dissolution and redox, in the proposed sludge washing processes (caustic leaching or oxidative leaching) was not understood, nor could it be predicted.

Our research thus far has consisted of three major components: 1) characterization of $\mathrm{Cr}$ species in acidic to highly alkaline solutions, 2) determination and modeling of the solubility of $\mathrm{Cr}(\mathrm{OH})_{3}(\mathrm{am})$ in acidic $(\mathrm{pH}$ $2.8)$ to highly alkaline conditions $(10.5 \mathrm{~m} \mathrm{NaOH})$ and mixed electrolytes containing nitrate, hydroxide and phosphate, and 3) study of the oxidation of $\mathrm{Cr}(\mathrm{III})$ by $\mathrm{H}_{2} \mathrm{O}_{2}$ and persulfate in alkaline solutions. These studies have been conducted in an integrated manner focused on understanding the effect of speciation on chemical behavior (solubility and redox). To enhance the application of our results to "realworld" problems, we compared and tested our results with those from actual tank sludge washing supported by the Tanks Focus Area (TFA). Accomplishments under this EMSP have been communicated in detail in the forms of journal articles, national conference presentations, and regular technical progress reports. The following are only brief summaries and highlights.

\section{Speciation of $\mathrm{Cr}$ (III) in Acidic to Strongly Alkaline Solutions}

Chromatographic Separation of Cr(III) Oligomers. Several methods have been developed to isolate macro amounts of $\mathrm{Cr}$ (III) oligomers using chromatographic techniques. This allowed us to investigate the chemical speciation, the structures of the separated oligomers, and the oxidation of isolated oligomers.

The effect of solution $\mathrm{pH}$ on the oligomerization was evaluated. A capillary electrophoresis approach was also developed to separate minor quantities of the oligomers and to verify the resolution and separation by chromatography [Friese et al. 2002].

Characterization of Cr(III) species. The separated $\mathrm{Cr}$ (III) species were characterized by a variety of methods, including UV-VIS, X-ray absorption spectroscopy (EXAFS), and capillary electrophoresis (CE). Some of our selected results are presented below.

The UV-Vis absorption spectra of solutions containing the separated $\mathrm{Cr}$ (III) species (separated by ion exchange) are shown in Figure 1. The energy shift (toward a longer wavelength) and the intensity enhancement of the absorption bands, from the monomer through dimer, trimer, and tetramer, to the aged/unseparated solution are interpreted in the context of the structures of the $\mathrm{Cr}$ (III) species and the ligand field theory [Rao et al. 2002]. 


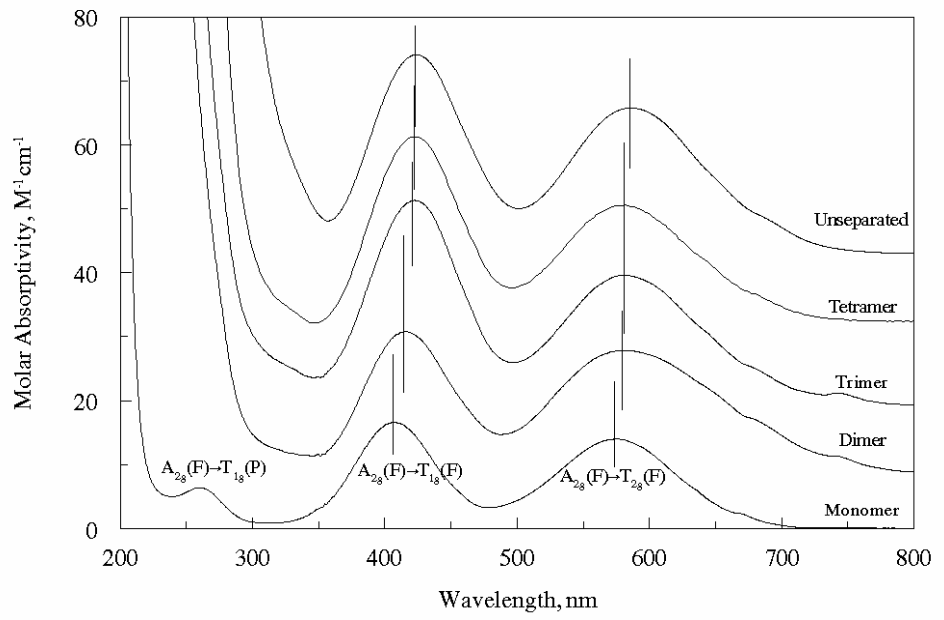

Figure 1. UV/Vis absorption spectra of $\mathrm{Cr}$ (III) monomer, dimer, trimer, tetramer and unseparated $\mathrm{Cr}$ (III) solutions. The spectra are shifted along y-axis for better viewing.

The UV-VIS absorption bands of the Cr(III) oligomers are quite broad. Consequently, absorption maxima of the separated fractions alone do not guarantee that a single $\mathrm{Cr}$ (III) species has been isolated. Yet isolation of a single species is important for resolving EXAFS spectra and for our oxidation studies. Therefore, we have used CE as an additional "quality assurance check" and have verified the purity of our isolated fractions of $\mathrm{Cr}$ (III) oligomers. Chromatograms of $\mathrm{Cr}$ solutions indicate that the charge density of the oligomers increases with the degree of polymerization [Friese et al. 2002].

Figure 2 shows the Fourier transforms of the EXAFS spectra of a few $\mathrm{Cr}$ (III) solution samples. Figure 2a shows the results for the separate $d$ monomer in the solution and on the ion exchange resin. The best fit indicates that there are six oxygens around the $\mathrm{Cr}$ at $1.97 \AA$, but no $\mathrm{Cr}$ at $3 \AA$, confirming the monomeric nature of this $\mathrm{Cr}$ (III) species. On the other hand, Figure $2 \mathrm{~b}$ indicates that the separated $\mathrm{Cr}$ (III) dimer, both in solution and on the resin, have one $\mathrm{Cr}$ at $2.97 \AA$, confirming the dimeric nature of this species. Figure $2 \mathrm{c}$ shows the effect of alkalinity on the oligomerization of $\mathrm{Cr}$ (III) in acidic to highly alkaline solutions. All the spectra show an oxygen shell (6 oxygen atoms) at around $1.99 \AA$. In all but the spectra for the solution with $\mathrm{pH} 2$, there is the feature $(\sim 2.99 \AA)$ that results from the $\mathrm{Cr}$-Cr scattering. The intensity of the $\mathrm{Cr}-\mathrm{Cr}$ scattering increases as the alkalinity is increased. This demonstrates that the oligomerization of $\mathrm{Cr}$ (III) is facilitated by higher alkalinity. Such an effect has a significant impact on the solubility of $\mathrm{Cr}(\mathrm{III})$ in alkaline solutions, which is described in subsequent discussions on solubility.

Based on the characterization under this EMSP project and the information in the literature [Spiccia et al. 1987, Finholt et al. 1981], the proposed structures of the dimer, trimer, and tetramer of Cr(III) are shown in Figure 3. 

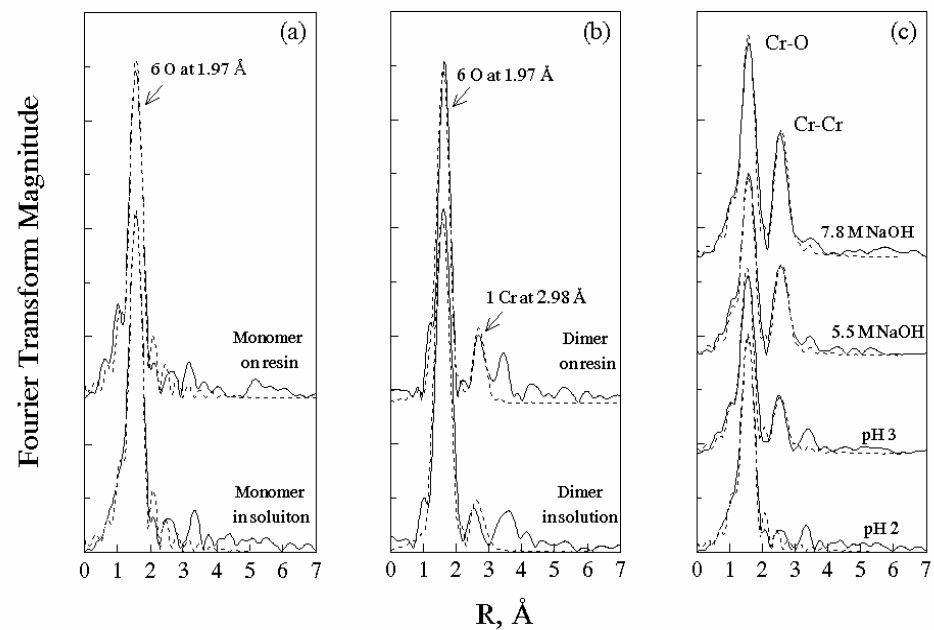

Figure 2. The Fourier transforms of the EXAFS spectra of $\mathrm{Cr}$ (III) solutions. Monomer in solution and on resin (a), dimer in solution and on resin ( b), and $\mathrm{Cr}$ (III) solutions of different alkalinity (c). Solid line: experimental; dashed line: fit.

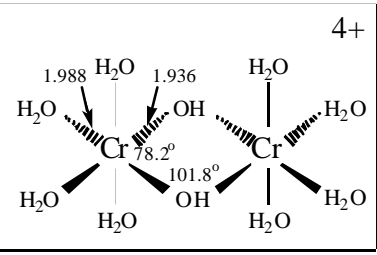

(a)

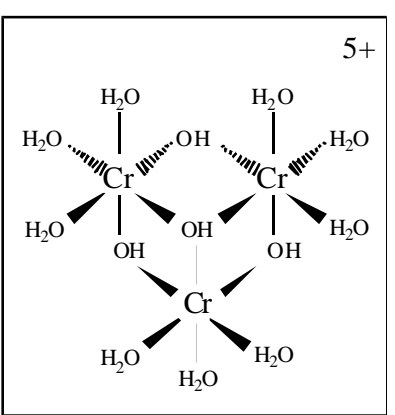

(c)

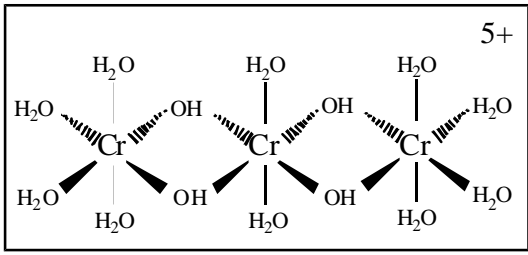

(b)

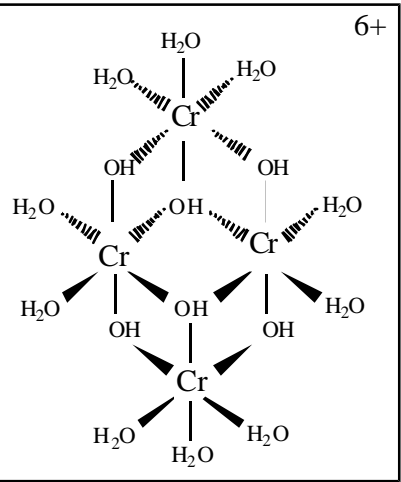

(d)

Figure 3. Structures of $\mathrm{Cr}(\mathrm{III})$ dimer (a), trimer (b, c) and tetramer (d). The bond lengths (in $\AA$ ) and angles for the dimer are from Spiccia et al. [1987]. The $\mathrm{Cr}-\mathrm{Cr}$ distance in the dimer is $3.006 \AA$. 
Chromium (III) hydroxide solids aged in solutions of different alkalinity, at different temperatures, and for different lengths of time were characterized by EXAFS and IR. Figure 4 shows that, in a manner similar to the aqueous species, the nature of the $\mathrm{Cr}$ (III) hydroxide solids also depends on the alkalinity, temperature, and aging time. These results are supported by the results from IR spectroscopy [Zhang et al. 2004].
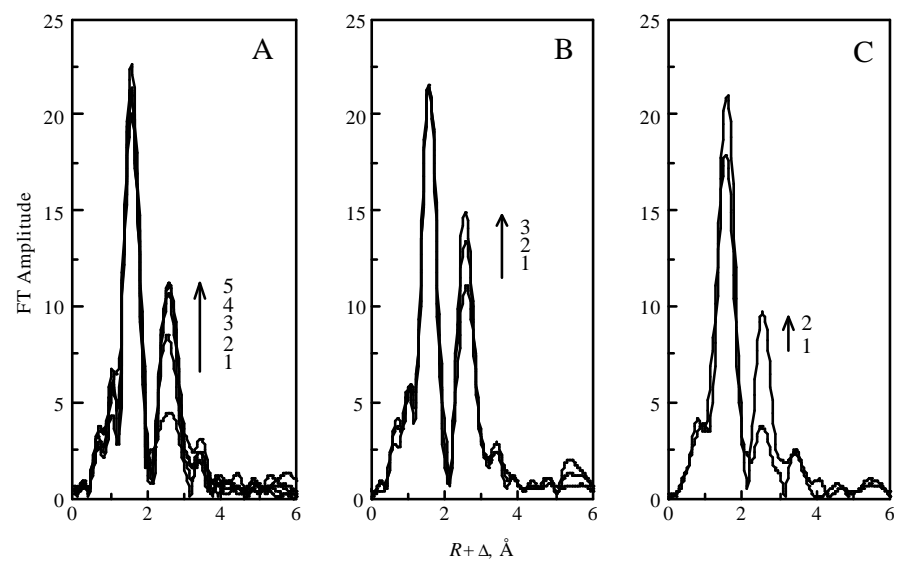

Figure 4. Fourier transform amplitude of $\mathrm{Cr}$ (III) hydroxide solids prepared under different conditions. (A) $\mathrm{Cr}(\mathrm{OH})_{3}(\mathrm{~s})$ aged at $25{ }^{\circ} \mathrm{C}$ for more than 130 days in solutions of different $[\mathrm{NaOH}]$. From 1 to 5: $\mathrm{pH}$ 9, $1.5 \mathrm{M}, 3 \mathrm{M}, 5.5 \mathrm{M}$ and $6 \mathrm{M} \mathrm{NaOH}$. (B) $\mathrm{Cr}(\mathrm{OH})_{3}(\mathrm{~s})$ aged in $5.5 \mathrm{M}$ $\mathrm{NaOH}$ at different temperatures. From 1 to 3: 25,50 and $70{ }^{\circ} \mathrm{C}$. $(\mathrm{C}) \mathrm{Cr}(\mathrm{OH})_{3}(\mathrm{~s})$ precipitated from $5 \mathrm{M} \mathrm{NaOH}$ at $25^{\circ} \mathrm{C} .1$ - freshly precipitated; 2 - aged for 131 days.

\section{Impact of Speciation, Ionic Strength, and Mixed Electrolytes on $\mathrm{Cr}(\mathrm{OH})_{3}(\mathrm{am})$ Solubility and the Development of Thermodynamic Model}

The solubility of $\mathrm{Cr}(\mathrm{OH})_{3}(\mathrm{am})$ was measured in $\mathrm{NaOH}(0.003$ to $10.5 \mathrm{~m})$ and mixed/concentrated $\mathrm{NaOH} / \mathrm{NaNO}_{3}$ and $\mathrm{NaOH} / \mathrm{Na}$-phosphate solutions at $22 \pm 2{ }^{\circ} \mathrm{C}$ [Rai et al. 2002, 2004]. A combination of techniques (XANES, Raman spectroscopy, absorptive stripping voltammetry, thermodynamic analyses of solubility data) was used to identify aqueous species and to confirm that the soluble $\mathrm{Cr}$ was present as $\mathrm{Cr}(\mathrm{III})$. Total chemical analyses, XRD, XAS, Raman spectroscopy, and thermodynamic analyses of solubility data were used to identify the solid phases at equilibrium.

$\mathrm{Cr}(\mathrm{III})-\mathrm{Na}^{+}-\mathbf{H}^{+}-\mathrm{OH}^{-}-\mathbf{H}_{2} \mathbf{O}$ system. The aqueous $\mathrm{Cr}$ concentrations in equilibrium with $\mathrm{Cr}(\mathrm{OH})_{3}(\mathrm{am})$ increase dramatically with an increase in $\mathrm{NaOH}$ concentrations (Figure 4). Based on the findings in our speciation studies and the thermodynamic analyses of the data, we could model this observed solubility behavior in relatively concentrated $\mathrm{NaOH}$ solutions by invoking two dominant $\mathrm{Cr}(\mathrm{III})$ species, $\mathrm{Cr}(\mathrm{OH})_{4}$ and $\mathrm{Cr}_{2} \mathrm{O}_{2}(\mathrm{OH})_{4}{ }^{2-}$, and by including Pitzer ion-interaction parameters for $\mathrm{Na}^{+}-\mathrm{Cr}(\mathrm{OH})_{4}{ }^{-}$and $\mathrm{Na}^{+}-$ $\mathrm{Cr}_{2} \mathrm{O}_{2}(\mathrm{OH})_{4}{ }^{2-}$. As shown in Figure 4, the model prediction satisfactorily describes the observed solubility. In order to verify and develop a more comprehensive model applicable from acidic to highly alkaline conditions, solubility studies were also conducted as a function of $\mathrm{pH}(2.8-14)$. In addition to the species listed above for $\mathrm{NaOH}>0.001 \mathrm{~m}, \mathrm{CrOH}^{2+}$ and $\mathrm{Cr}(\mathrm{OH})_{3}(\mathrm{aq})$ were required to provide a reliable prediction of the observed solubility behavior (Fig. 5). 

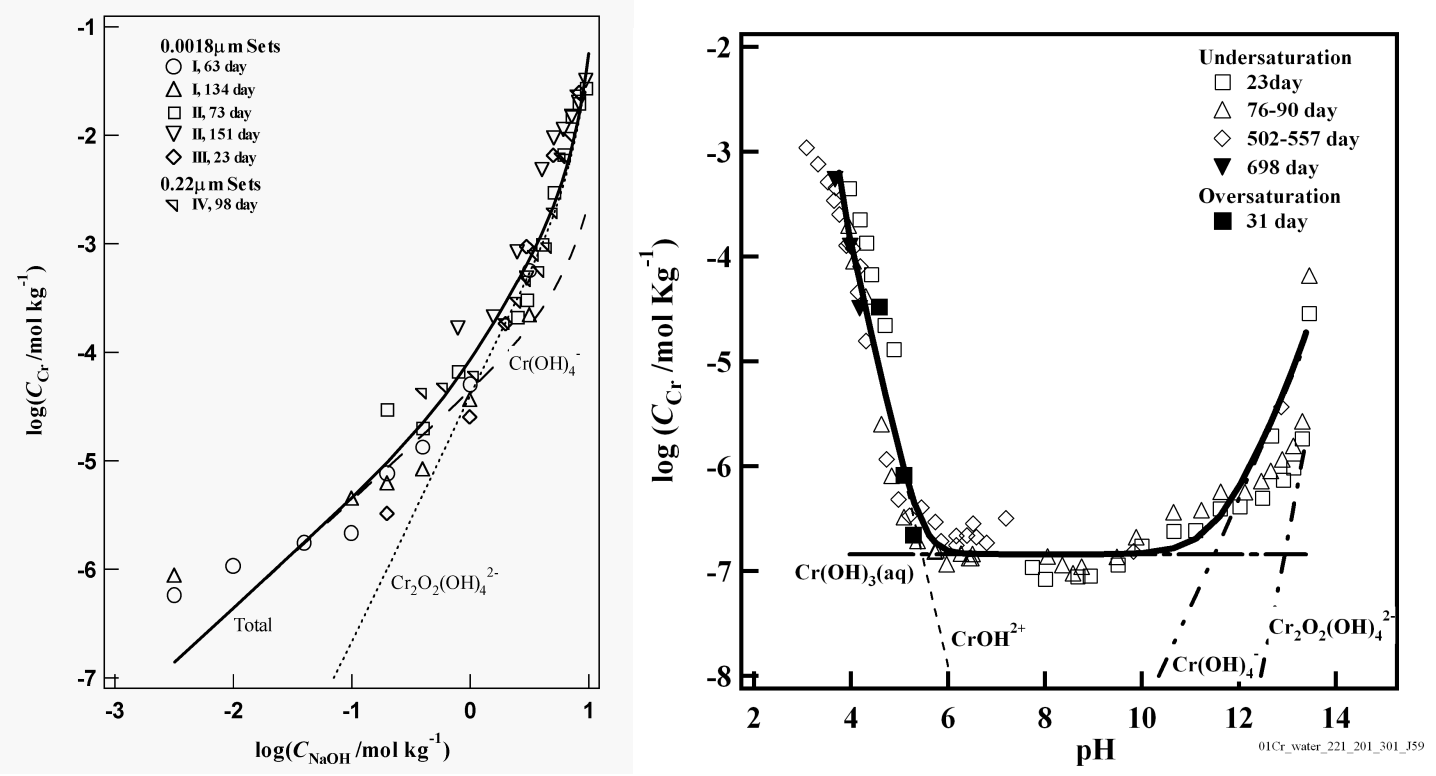

Figure 5. Aqueous chromium concentrations from $\mathrm{Cr}(\mathrm{OH})_{3}(\mathrm{am})$ suspensions in $\mathrm{NaOH}$ (Left) and as a function of $\mathrm{pH}$ (Right). Lines represent predicted concentrations using the thermodynamic data reported in Rai et al. [2002 and 2004].

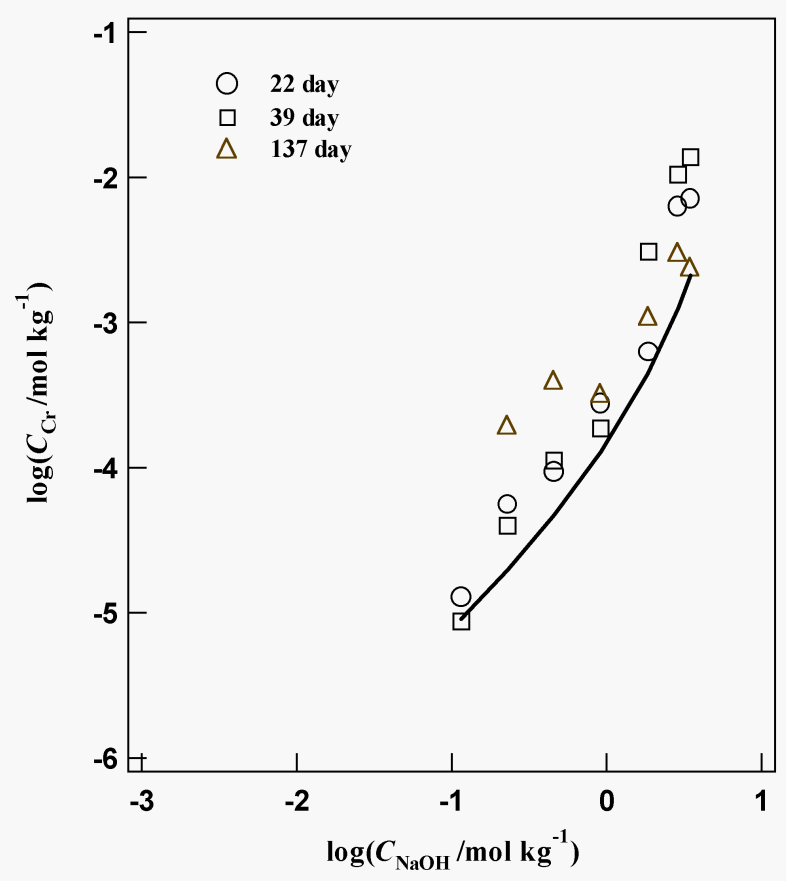

Figure 6. Aqueous chromium concentrations from $\mathrm{Cr}(\mathrm{OH})_{3}(\mathrm{am})$ suspensions in $4.6 \mathrm{~m} \mathrm{NaNO}_{3}$ containing different concentrations of $\mathrm{NaOH}$. Lines represent predicted concentrations using the thermodynamic data reported in Rai et al. [2002 and 2004]. 
$\mathrm{Cr}$ (III)-Na ${ }^{+}-\mathrm{H}^{+}-\mathrm{OH}^{-}-\mathrm{NO}_{3}{ }^{-} \mathrm{H}_{2} \mathrm{O}$ system. The $\mathrm{Cr}$ (III)-hydroxide model was further tested using the experimental $\mathrm{Cr}(\mathrm{OH})_{3}(\mathrm{am})$ solubility in mixed $\mathrm{NaOH}$ and $\mathrm{NaNO}_{3}$ solutions with $\mathrm{NaOH}$ varying up to 3.5 $\mathrm{m}$ and $\mathrm{NaNO}_{3}$ varying up to $7.5 \mathrm{~m}$ (Rai et al. 2002). The $\mathrm{Cr}$ concentrations predicted by the model were in reasonably close agreement with the observed concentrations in mixed $\mathrm{NaOH}-\mathrm{NaNO}_{3}$ solutions (Figure 6). The thermodynamic parameters for the dissolution of $\mathrm{Cr}(\mathrm{OH})_{3}(\mathrm{am})$ in these systems, along with the ion interaction parameters, are provided in detail in Rai et al. [2002]

$\mathrm{Cr}(\mathrm{III})-\mathrm{Na}^{+}-\mathrm{OH}^{-}-\mathrm{H}_{2} \mathrm{PO}_{4}{ }^{-}-\mathrm{HPO}_{4}{ }^{2-}-\mathrm{PO}_{4}{ }^{3-}-\mathrm{H}_{2} \mathrm{O}$ system. Solubility studies of $\mathrm{Cr}(\mathrm{OH})_{3}(\mathrm{am})$ as a function of $\mathrm{pH}(2.8-14)$ at fixed $0.05 \mathrm{~m}$ phosphate and as a function of phosphate (varying up to $1.04 \mathrm{~m}$ ) at fixed $\mathrm{pH}$ values of 6,10 , or 13 were conducted to determine the nature of $\mathrm{Cr}$ (III)-phosphate species and their impact on the solubility of $\mathrm{Cr}(\mathrm{OH})_{3}(\mathrm{am})$ [Rai et al. 2004]. Phosphate significantly increased the solubility of $\mathrm{Cr}(\mathrm{III})$ in a very large range of $\mathrm{pH}$ values, and the increases were dramatic in the near neutral region (Figure 7). The study showed that phosphate does not form $\mathrm{Cr}$ (III)-phosphate solids in the alkaline region, even in the presence of as high concentrations as $0.6 \mathrm{~m} \mathrm{Na}_{3} \mathrm{PO}_{4}$, and that $\mathrm{Cr}(\mathrm{OH})_{3}(\mathrm{am})$ is the stable phase. Contrary to the data recently reported in the literature [Ziemniak et al. 1998], only a limited number of aqueous species $\left[\mathrm{Cr}(\mathrm{OH})_{3} \mathrm{H}_{2} \mathrm{PO}_{4}{ }^{-}, \mathrm{Cr}(\mathrm{OH})_{3}\left(\mathrm{H}_{2} \mathrm{PO}_{4}\right)_{2}{ }^{2-}\right)$, and $\left.\mathrm{Cr}(\mathrm{OH})_{3} \mathrm{HPO}_{4}{ }^{2-}\right]$ with up to about four orders of magnitude lower values for the formation constants of these species are required to explain $\mathrm{Cr}(\mathrm{III})$-phosphate reactions in a wide range of $\mathrm{pH}$ and phosphate concentrations.
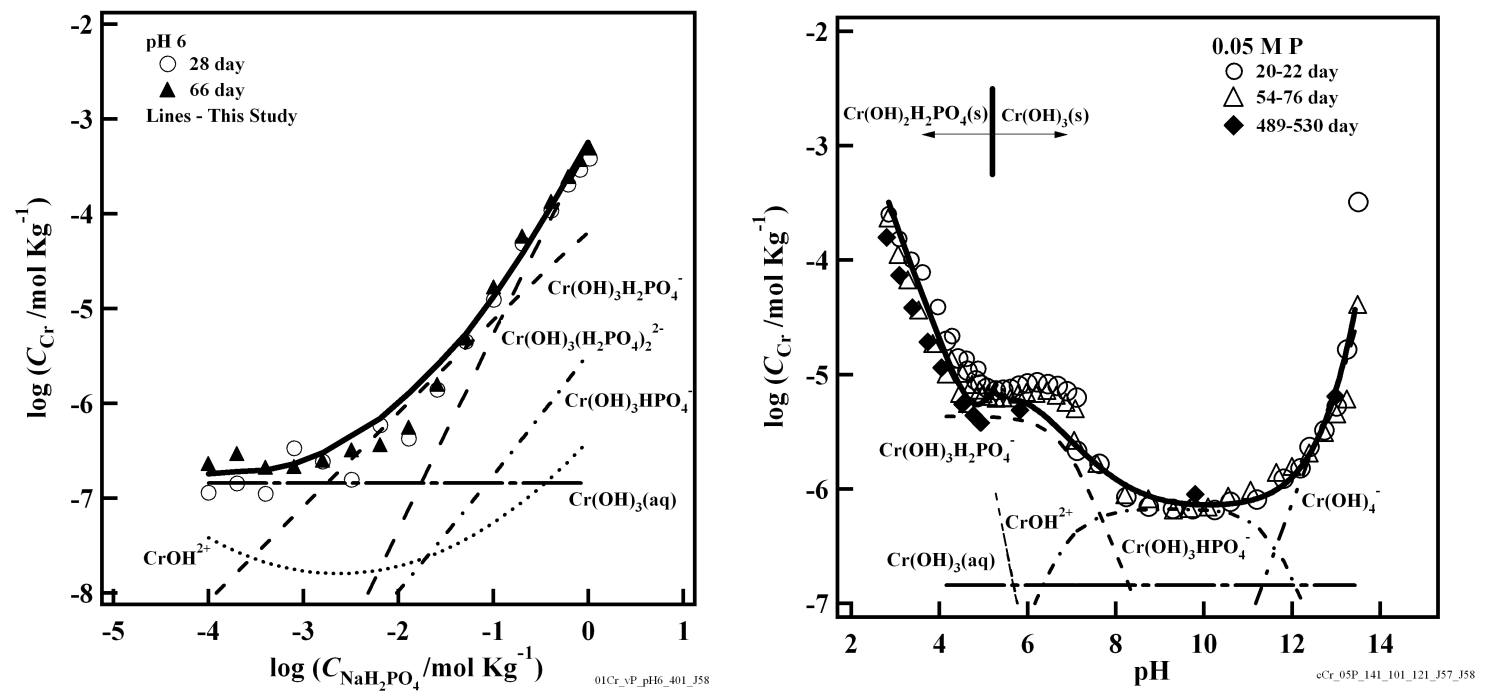

Figure 7. Aqueous chromium concentrations as a function of $\mathrm{pH}$ from $\mathrm{Cr}(\mathrm{OH})_{3}(\mathrm{am})$ or $\mathrm{Cr}(\mathrm{OH})_{2} \mathrm{H}_{2} \mathrm{PO}_{4}(\mathrm{am})$ suspensions in $0.05 \mathrm{~m}$ phosphate (Left) and from $\mathrm{Cr}(\mathrm{OH})_{3}(\mathrm{am})$ suspensions as function of phosphate concentrations at fixed $\mathrm{pH}$ valure of 6 (Right). Lines represent predicted concentrations using the thermodynamic data reported in Rai et al. [2002 and 2004].

\section{Thermodynamic model for the system $\mathrm{Cr}(\mathrm{III})-\mathrm{Na}^{+}-\mathrm{OH}^{-}-\mathrm{NO}_{3}{ }^{-}-\mathrm{H}_{2} \mathrm{PO}_{4}{ }^{-}-\mathrm{HPO}_{4}{ }^{2-}-\mathrm{PO}_{4}{ }^{3-}-\mathrm{H}_{2} \mathrm{O}$. A} thermodynamic model based on the data discussed above was developed for tank-like chemical environments containing concentrated hydroxide, nitrate, and phosphate (Table 2; Rai et al. 2002, 2004). This model provides reliable predictions for acidic $(\mathrm{pH} 2.8)$ to highly alkaline conditions $(10.5 \mathrm{~m} \mathrm{NaOH})$, and mixed electrolytes containing nitrate and hydroxide (with $\mathrm{NaOH}$ varying up to $3.5 \mathrm{~m}$ and $\mathrm{NaNO}_{3}$ varying up to $7.5 \mathrm{~m}$ ) and phosphate and hydroxide (with $\mathrm{NaOH}$ varying up to $0.3 \mathrm{~m}$ and phosphate varying up to $1.04 \mathrm{~m}$ ). 
Table 2. Pitzer ion-interaction parameters and other thermodynamic data for $\mathrm{Cr}(\mathrm{OH})_{3}(\mathrm{am})$ solubility in concentrated hydroxide, nitrate, and phosphate systems.

\begin{tabular}{|c|c|c|c|c|c|}
\hline \multirow[b]{2}{*}{ Species } & \multicolumn{2}{|c|}{ Binary Parameters } & \multirow[b]{2}{*}{$\beta^{(2)}$} & \multirow[b]{2}{*}{$c^{\varnothing}$} & \multirow[b]{2}{*}{ Reference } \\
\hline & $\beta^{(0)}$ & $\beta^{(1)}$ & & & \\
\hline $\mathrm{Na}^{+}-\mathrm{OH}^{-}$ & 0.0864 & 0.253 & 0.00 & 0.0044 & Pitzer 1991 \\
\hline $\mathrm{Na}^{+}-\mathrm{Cr}(\mathrm{OH})_{4}^{-}$ & 0.045 & 0.31 & 0.00 & -0.003 & Rai et al. 2002 \\
\hline $\mathrm{Na}^{+}-\mathrm{Cr}_{2} \mathrm{O}_{2}(\mathrm{OH})_{4}^{2-}$ & 0.41 & 0.7 & 0.00 & -0.03768 & Rai et al. 2002 \\
\hline $\mathrm{Na}^{+}-\mathrm{PO}_{4}^{3-}$ & 0.1781 & 3.851 & 0.00 & -0.0515 & Pitzer 1991 \\
\hline $\mathrm{Na}^{+}-\mathrm{HPO}_{4}{ }^{2-}$ & -0.0583 & 1.4655 & 0.00 & 0.02938 & Pitzer 1991 \\
\hline $\mathrm{Na}^{+}-\mathrm{H}_{2} \mathrm{PO}_{4}^{-}$ & -0.0533 & 0.0396 & 0.00 & 0.00795 & Pitzer 1991 \\
\hline $\mathrm{Na}^{+}-\mathrm{Cr}(\mathrm{OH})_{3} \mathrm{HPO}_{4}{ }^{2-}$ & -0.0583 & 1.4655 & 0.00 & 0.02938 & Rai et al. 2004 \\
\hline $\mathrm{Na}^{+}-\mathrm{Cr}(\mathrm{OH})_{3} \mathrm{H}_{2} \mathrm{PO}_{4}^{-}$ & -0.0533 & 0.0396 & 0.00 & 0.00795 & Rai et al. 2004 \\
\hline \multirow[t]{3}{*}{$\mathrm{Na}^{+}-\mathrm{Cr}(\mathrm{OH})_{3}\left(\mathrm{H}_{2} \mathrm{PO}_{4}\right)_{2}{ }^{2-}$} & -0.0583 & 1.4655 & 0.00 & 0.02938 & Rai et al. 2004 \\
\hline & \multicolumn{5}{|c|}{ Common-Ion Ternary Parameters } \\
\hline & \multicolumn{5}{|l|}{ Value } \\
\hline $\mathrm{OH}^{-}-\mathrm{Cr}(\mathrm{OH})_{4}^{-}$ & \multicolumn{2}{|l|}{0.014} & & & Rai et al. 2002 \\
\hline $\mathrm{OH}^{-}-\mathrm{Cr}(\mathrm{OH})_{4}^{-}-\mathrm{Na}^{+}$ & \multicolumn{2}{|l|}{-0.0048} & & & Rai et al. 2002 \\
\hline $\mathrm{H}^{+}-\mathrm{H}_{3} \mathrm{PO}_{4}(\mathrm{aq})$ & \multicolumn{2}{|l|}{0.29} & & & Pitzer and Silvester 1976 \\
\hline $\mathrm{H}_{3} \mathrm{PO}_{4}(\mathrm{aq})-\mathrm{H}_{3} \mathrm{PO}_{4}(\mathrm{aq})$ & \multicolumn{2}{|l|}{0.053} & & & Pitzer and Silvester 1976 \\
\hline $\mathrm{H}_{2} \mathrm{PO}_{4}^{-}-\mathrm{H}_{3} \mathrm{PO}_{4}(\mathrm{aq})$ & \multicolumn{2}{|l|}{-0.4} & & & Pitzer and Silvester 1976 \\
\hline \multirow[t]{2}{*}{$\mathrm{H}^{+}-\mathrm{Na}^{+}$} & 0.036 & & & & Pitzer 1991 \\
\hline & \multicolumn{4}{|c|}{ Equilibrium Constants } & \\
\hline \multicolumn{3}{|l|}{ Reaction } & \multicolumn{2}{|c|}{$\log K^{0}$} & \\
\hline \multicolumn{3}{|c|}{$\mathrm{Cr}(\mathrm{OH})_{3}(\mathrm{am}) \int \mathrm{Cr}(\mathrm{OH})_{3}$} & \multicolumn{2}{|c|}{-6.84} & Rai et al. 1987, 2004 \\
\hline \multicolumn{3}{|c|}{$\mathrm{Cr}(\mathrm{OH})_{3}(\mathrm{am})+\mathrm{OH}^{-} \int \mathrm{Cr}(\mathrm{OH})_{4}^{-}$} & \multicolumn{2}{|c|}{$-4.36 " 0.24$} & Rai et al. 2002 \\
\hline \multicolumn{3}{|c|}{$2 \mathrm{Cr}(\mathrm{OH})_{3}(\mathrm{am})+2 \mathrm{OH}^{-} \int \mathrm{Cr}_{2} \mathrm{O}_{2}(\mathrm{OH})_{4}{ }^{2-}+2 \mathrm{H}_{2} \mathrm{O}$} & \multicolumn{2}{|c|}{$-5.24 " 0.24$} & Rai et al. 2002 \\
\hline \multicolumn{3}{|c|}{$\mathrm{Cr}(\mathrm{OH})_{3}(\mathrm{am})+2 \mathrm{H}^{+} \int \mathrm{CrOH}^{2+}+2 \mathrm{H}_{2} \mathrm{O}$} & \multicolumn{2}{|c|}{$4.09 " 0.38$} & Rai et al. 2004 \\
\hline \multicolumn{3}{|c|}{$\mathrm{Cr}(\mathrm{OH})_{2} \mathrm{H}_{2} \mathrm{PO}_{4}(\mathrm{am})+\mathrm{H}^{+} \int \mathrm{CrOH}^{2+}+\mathrm{H}_{2} \mathrm{PO}_{4}^{-}+\mathrm{H}_{2} \mathrm{O}$} & \multicolumn{2}{|c|}{$-2.52 " 0.21$} & Rai et al. 2004 \\
\hline \multicolumn{3}{|c|}{$\mathrm{Cr}(\mathrm{OH})_{3}(\mathrm{am})+\mathrm{HPO}_{4}^{2-} \int \mathrm{Cr}(\mathrm{OH})_{3} \mathrm{HPO}_{4}^{2-}$} & \multicolumn{2}{|c|}{$-4.87 " 0.3$} & Rai et al. 2004 \\
\hline \multicolumn{3}{|c|}{$\mathrm{Cr}(\mathrm{OH})_{3}(\mathrm{am})+\mathrm{H}_{2} \mathrm{PO}_{4}^{-} \int \mathrm{Cr}(\mathrm{OH})_{3} \mathrm{H}_{2} \mathrm{PO}_{4}^{-}$} & \multicolumn{2}{|c|}{$-4.06 " 0.3$} & Rai et al. 2004 \\
\hline \multicolumn{3}{|c|}{$\mathrm{Cr}(\mathrm{OH})_{3}(\mathrm{am})+2 \mathrm{H}_{2} \mathrm{PO}_{4}^{-} \int \mathrm{Cr}(\mathrm{OH})_{3}\left(\mathrm{H}_{2} \mathrm{PO}_{4}\right)_{2}{ }^{2-}$} & & $6 " 0.3$ & Rai et al. 2004 \\
\hline
\end{tabular}




\section{Impact of Speciation on Redox: Oxidation of Cr(III) by Peroxide and Persulfate}

Two oxidants were studied, peroxide $\left(\mathrm{H}_{2} \mathrm{O}_{2}\right)$ and the persulfate anion $\left(\mathrm{S}_{2} \mathrm{O}_{8}{ }^{-}\right)$. Peroxide is of interest because of its favorable reduction potential relative to $\mathrm{Cr}$ (III) oxidation to chromate, and because its use does not add unwanted components to the already complex waste stream. Persulfate is of interest because of work completed by Russian scientists on its oxidation of Cr(III) in alkaline systems. Krot et al. [1999] indicated that persulfate may be preferred over peroxide and other common oxidants because of its reactivity towards $\mathrm{Cr}$ (III) and because it could be applied such that little increase in waste volume occurred. However, for both hydrogen peroxide and persulfate, no mechanistic data were available prior to our work under this EMSP.

Oxidation of Aqueous Cr(III) Oligomers by $\mathrm{H}_{2} \mathrm{O}_{2}$ and Persulfate in Alkaline Solutions. The oxidation of $\mathrm{Cr}(\mathrm{III})$ was followed by monitoring the increase of $\mathrm{Cr}(\mathrm{VI})$ absorbance at $372 \mathrm{~nm}$. The oxidation was found to be the first order with respect to the concentrations of $\mathrm{Cr}(\mathrm{III})$ and $\mathrm{H}_{2} \mathrm{O}_{2}$. As to the dependency on the $\mathrm{OH}$ concentration, there seem to be two reaction pathways: the major one is inversely dependent on $[\mathrm{OH}]$, and the other independent of $[\mathrm{OH}]$ (insignificant). A general rate equation is written as

$$
\begin{aligned}
\mathrm{R}=-\mathrm{d}\left[\mathrm{Cr}_{\mathrm{n}}(\mathrm{III})\right] / \mathrm{dt}=\mathrm{n} \mathrm{d}[\mathrm{Cr}(\mathrm{VI})] / \mathrm{dt} & =\mathrm{k}\left[\mathrm{Cr}_{\mathrm{n}}(\mathrm{III})\right]\left[\mathrm{H}_{2} \mathrm{O}_{2}\right]\left(1 /[\mathrm{OH}]+\mathrm{k}^{\prime}\right) \\
& =\mathrm{k}_{\mathrm{OH}}\left[\mathrm{Cr}_{\mathrm{n}}(\mathrm{III})\right]\left[\mathrm{H}_{2} \mathrm{O}_{2}\right] \\
& =\mathrm{k}_{\mathrm{obs}}\left[\mathrm{Cr}_{\mathrm{n}}(\mathrm{III})\right]
\end{aligned}
$$

where $\mathrm{n}=1,2$ and 3 for monomer, dimer, and trimer, respectively. Examples of the plots of $\mathrm{k}_{\mathrm{obs}} \mathrm{vs}$. $\left[\mathrm{H}_{2} \mathrm{O}_{2}\right]$ are shown in Figure 8 for the monomer, dimer, and trimer, respectively. It can be seen that, at the same concentrations of $\mathrm{H}_{2} \mathrm{O}_{2}$ and $\mathrm{NaOH}$, the oxidation rate decreases in the order monomer > dimer > trimer > higher ligomers.
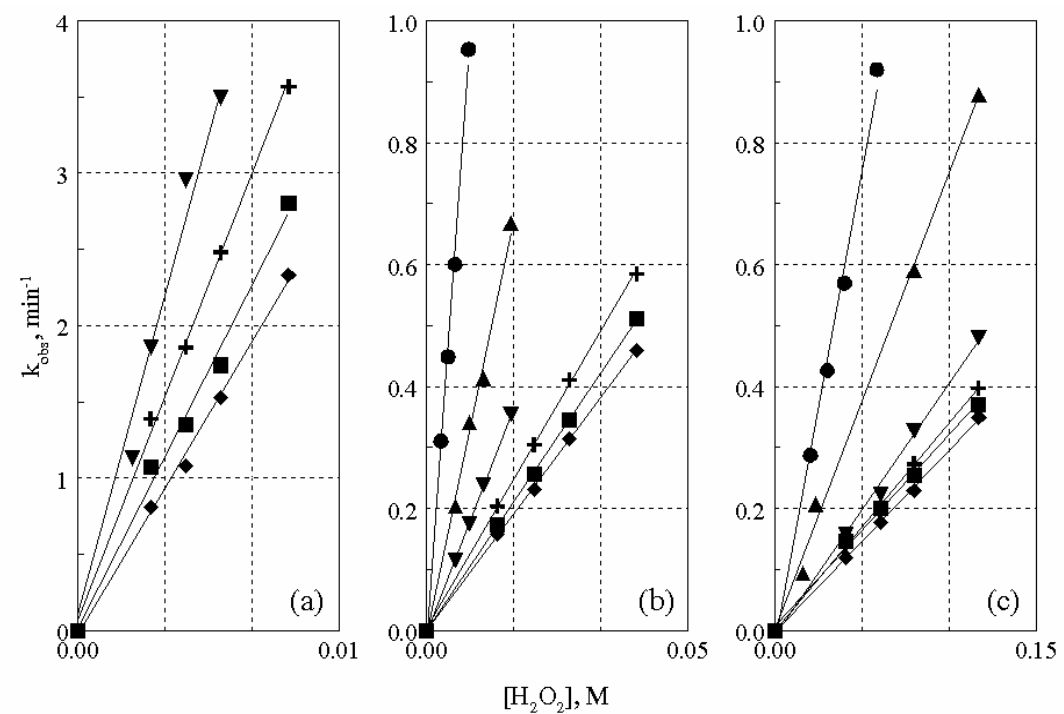

Figure 8. The pseudo first-order rate constant, $\mathrm{k}_{\mathrm{obs}}$, as a function of $\left[\mathrm{H}_{2} \mathrm{O}_{2}\right]$ at constant $[\mathrm{OH}]$. (a) monomer, (b) dimer, (c) trimer. Symbols: $[\mathrm{OH}]=0.100 \mathrm{M}(?), 0.252 \mathrm{M}$ (? ), $0.504 \mathrm{M}$ (?), 0.756 $\mathrm{M}(+), 1.00 \mathrm{M}\left(\begin{array}{l}1 \\ 1\end{array}\right), 1.18 \mathrm{M}(?)$. 
Values of the rate constant $\mathrm{k}$ [equation 1], calculated from these plots, are provided in Rao et al. [2002]. These values show that the oxidation rate decreases in the order monomer $>$ dimer $>$ trimer $>$ higher oligomers. If $\left[\mathrm{H}_{2} \mathrm{O}_{2}\right]=0.01 \mathrm{M}$ and $[\mathrm{NaOH}]=1.0 \mathrm{M}$, the time required for $50 \%$ oxidation $\left(\mathrm{t}_{1 / 2}\right.$, in minutes) would be in the order monomer $(0.2)<$ dimer (6) > trimer (22) > unseparated/aged Cr(III) (410). In a brief summary, our data [Rao et al. 2002] indicate that, 1) $\mathrm{H}_{2} \mathrm{O}_{2}$ can oxidize $\mathrm{Cr}$ (III) to $\mathrm{Cr}$ (VI) in alkaline solutions, 2) the oxidation probably occurs through a rate-determining step involving the breaking of the bridging bonds in the oligomers and the concomitant release of one hydroxyl group from the $\mathrm{Cr}$ (III) moiety upon the attack by $\mathrm{H}_{2} \mathrm{O}_{2}$, and 3) it is likely that more energy is required to break the bridging bonds in higher oligomers. Consequently, the redox reactivity of the $\mathrm{Cr}$ (III) species with $\mathrm{H}_{2} \mathrm{O}_{2}$ decreases as oligomerization proceeds.

Oxidation of $\mathrm{Cr}$ (III) by persulfate follows a different kinetics mechanism [Friese et al. 2004). This is most easily demonstrated by comparing Figure 9 with the results of $\mathrm{Cr}$ (III) oxidation by peroxide [Figure 8]. When $[\mathrm{NaOH}]<1 \mathrm{M}$, the reaction rate is best described by multiple first-order processes. When $[\mathrm{NaOH}]$ $>1 \mathrm{M}, \mathrm{Cr}(\mathrm{III})$ oxidation by persulfate is best described by a single first-order process; note that the linear dependence on oxidant concentration observed with peroxide is only observed with persulfate at very high concentrations of $\mathrm{NaOH}$ (e.g., $\sim 5 \mathrm{M} \mathrm{NaOH})$.

Detailed investigations over wide ranges of conditions (e.g., [ $\mathrm{NaOH}]$, [persulfate], and temperature) have revealed the following important conclusions: 1) There is a very rapid oxidation step probably involving the sulfate radical $\left(\mathrm{SO}_{4}{ }^{-}\right)$[Koltoff 1951]. The conditions that favor oxidation by the persulfate radical include $[\mathrm{NaOH}]<1 \mathrm{M}$, and temperatures elevated to at least $30^{\circ} \mathrm{C}$. 2) A second process in the oxidation of $\mathrm{Cr}$ (III) by persulfate follows Michelis-Menton-type kinetics, suggesting the formation of an intermediate species.

For the oxidation of aqueous $\mathrm{Cr}$ (III) oligomers with both peroxide and persulfate, there are two implications that are of great significance to the design of oxidative sludge washing to remove $\mathrm{Cr}$ : 1) Any processes that can break down the oligomers will facilitate the oxidation, and thus the dissolution of $\mathrm{Cr}$; and 2) Although oxidation occurs in alkaline solutions, high concentrations of $\mathrm{NaOH}$ will slow the oxidation.

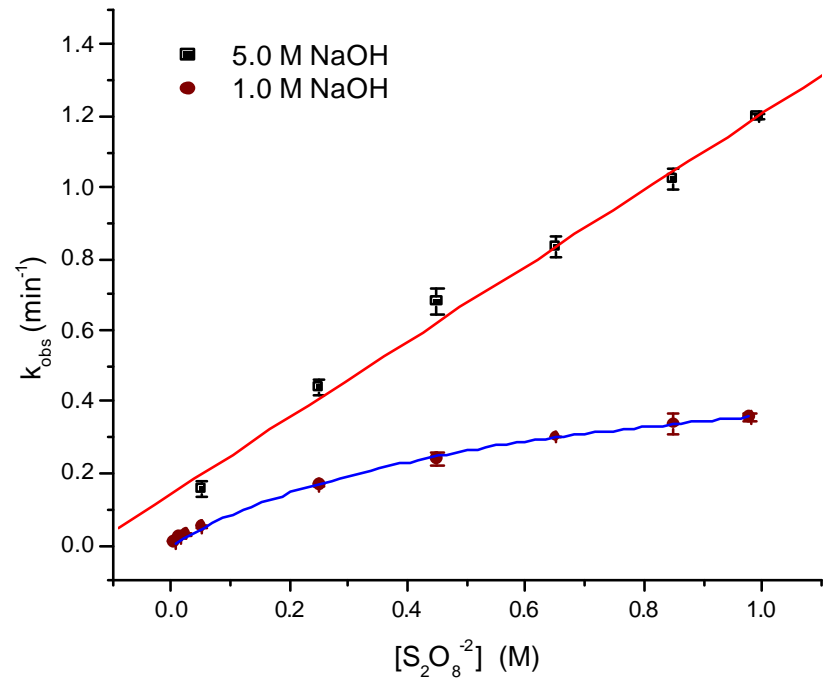

Figure 9. Observed rate constants for the oxidation of $\mathrm{Cr}$ (III) by persulfate in $\mathrm{NaOH}$. [Cr(III)] = $1 \times 10^{-4} \mathrm{M}, \mathrm{T}=22^{\circ} \mathrm{C}$. Note that, unlike oxidation by peroxide, the observed reaction rates are only linear with respect to persulfate concentration when $[\mathrm{NaOH}]$ is quite large. 
Oxidation of $\mathrm{Cr}$ (III) Hydroxide Solids by $\mathrm{H}_{2} \mathrm{O}_{2}$ in Alkaline Solutions . As Figure 10 shows, freshly precipitated $\mathrm{Cr}(\mathrm{III})$ hydroxide was oxidized most rapidly, indicated by the rapid increase of the absorbance of $\mathrm{Cr}(\mathrm{VI})$ at $372 \mathrm{~nm}$. Aging the solids decreased the rate of oxidation. The solids that were aged in solutions of higher concentrations of $\mathrm{NaOH}$ reacted with hydrogen peroxide more slowly. Based on the information obtained by EXAFS and IR, these results indicate that the solids with a higher degree of oligomerization are oxidized more slowly by hydrogen peroxide in alkaline solutions.

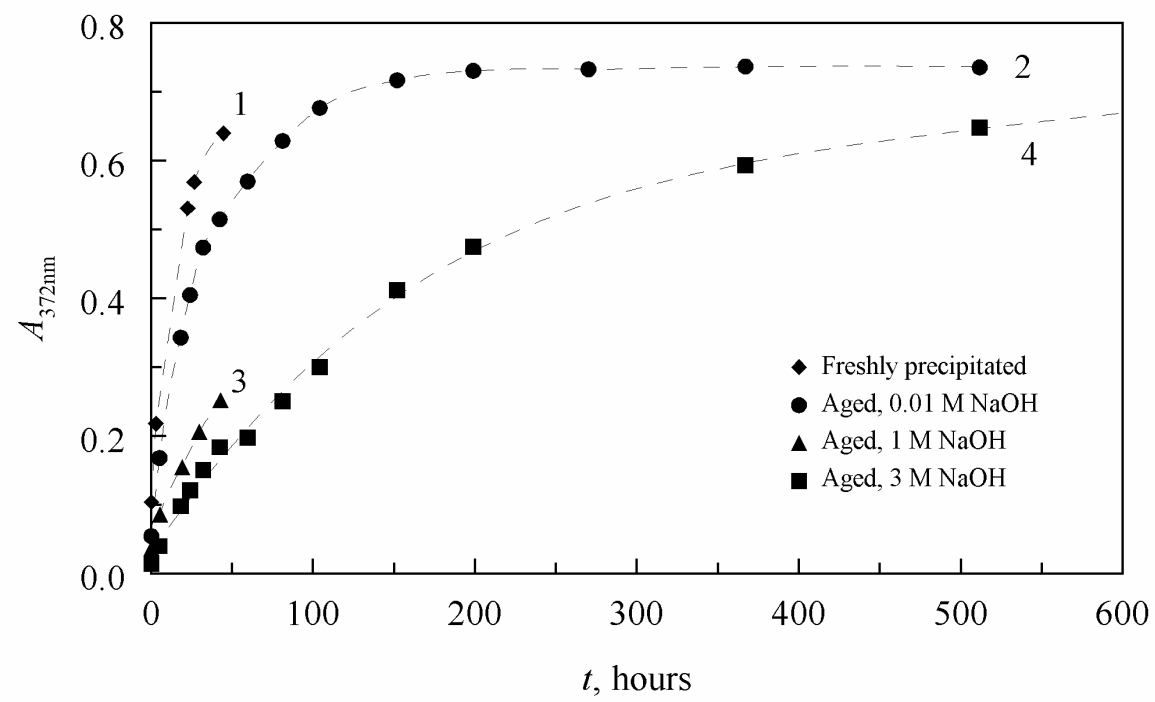

Figure 10. Oxidation of $\mathrm{Cr}(\mathrm{III})$ hydroxide solids by $\mathrm{H}_{2} \mathrm{O}_{2}$ in $1 \mathrm{M} \mathrm{NaOH}$ at $(22 \pm 2){ }^{\circ} \mathrm{C}$.

The trend observed for the oxidation of $\mathrm{Cr}$ (III) hydroxide solids parallels that previously observed for the $\mathrm{Cr}$ (III) solution species, i.e., the rate constants of the oxidation decrease as the degree of oligomerization becomes higher [Rao et al. 2002]. Full explanations for the observed order are not possible at present because the difficulty in defining concentrations in the heterogeneous systems does not allow us to derive reaction orders and the rate law for the studied reaction. Besides, further experiments are needed to obtain detailed structural information on the $\mathrm{Cr}$ (III) species in the solids and the point of attack by hydrogen peroxide.

\section{End-User Connection: Tests Against Data on Washed Solids from High-Level Tanks}

Ideally, the fundamental data developed under this EMSP project need to be tested with well-designed protocols of actual sludge washing. However, extensive studies with actual sludges are extremely expensive and beyond the scope of this EMSP funding. As a result, we decided to use the data that is available in technical reports from PNNL [Rapko et al. 1995; Lumetta et al. 1996a, 1997] on the washing of Hanford tank sludges. Although these data do not cover as wide a range of hydroxide concentrations or as rigidly controlled experimental conditions as we desire, they do provide a limited data set to test the applicability of fundamental data developed under the current EMSP.

In the study of the pretreatment of Hanford tank sludges supported by the TFA [Rapko et al. 1995; Lumetta et al. 1996a, 1997], in most cases three sequential washings were performed on sludges from 14 different Hanford tanks: 1) retrieval and dilute $\mathrm{NaOH}$ washes, 2) first caustic leach, and 3) second caustic leach. The sludges used in the TFA study represent four major chemical processing operations (REDOX, 
TBP, $\mathrm{BiPO}_{4}$, and PUREX). The washes parallel those being proposed for actually washing the sludges. Of these washes, the caustic washes $(3 \mathrm{MNaOH})$ are expected to dissolve most $\mathrm{Cr}$ (III) (e.g. see Fig. 5), and the second caustic wash especially very nearly represents the electrolytes for which we have a valid thermodynamic model. Therefore, we decided to compare the observed $\mathrm{Cr}$ concentrations in the caustic washes with those predicted using the thermodynamic model presented in Table 2. It should be mentioned that even the second caustic leachates (the third wash) from different sludges, in addition to containing 3 $\mathrm{M} \mathrm{NaOH}$, still contain differing concentrations of aluminum, nitrate, nitrite, and phosphate (e.g. phosphate concentrations vary from very low to as high as $0.03 \mathrm{M}$ in tank T104). As expected, the concentrations of ligands in retrieval washes and the first caustic wash are much higher than those in the second caustic wash (e.g., phosphate levels in dilute $\mathrm{NaOH}$ wash from tank $\mathrm{T} 104$ is $0.13 \mathrm{M}$ ). The comparison of the observed $\mathrm{Cr}$ concentrations in the caustic washes to the predicted $\mathrm{Cr}$ concentrations from our thermodynamic model is shown in Figure 11. The predicted $\mathrm{Cr}$ concentrations, assuming an equilibrium with $\mathrm{Cr}(\mathrm{OH})_{3}(\mathrm{am})$, were fairly close to that observed for the first caustic wash (about one order of magnitude lower for a few sludges), and in excellent agreement with that observed for the second caustic wash. However, the predicted concentrations were up to about three orders of magnitude lower than those observed in the dilute $\mathrm{NaOH}$ washes. At present, the exact reason for the significant disagreement for the dilute $\mathrm{NaOH}$ wash is not known, but we surmise it may result from the presence of $\mathrm{Cr}(\mathrm{VI})$, other eletrolytes (e.g., carbonate and sulfate) that were not included in the research investigations under the current EMSP project, and probably the leaching protocols. Nonetheless, the excellent agreement for the second caustic wash (and, to a lesser extent, the first caustic wash) is very encouraging and shows the practical importance of the data developed in this EMSP project for determining the effects of concentrations of different ligands and $\mathrm{NaOH}$ for opitimizing/predicting the solubilization of $\mathrm{Cr}$ (III) from different tanks. The thermodynamic parameters developed under the current program have been included in the TFA's Environmental Simulations Program for use by the site personnel.

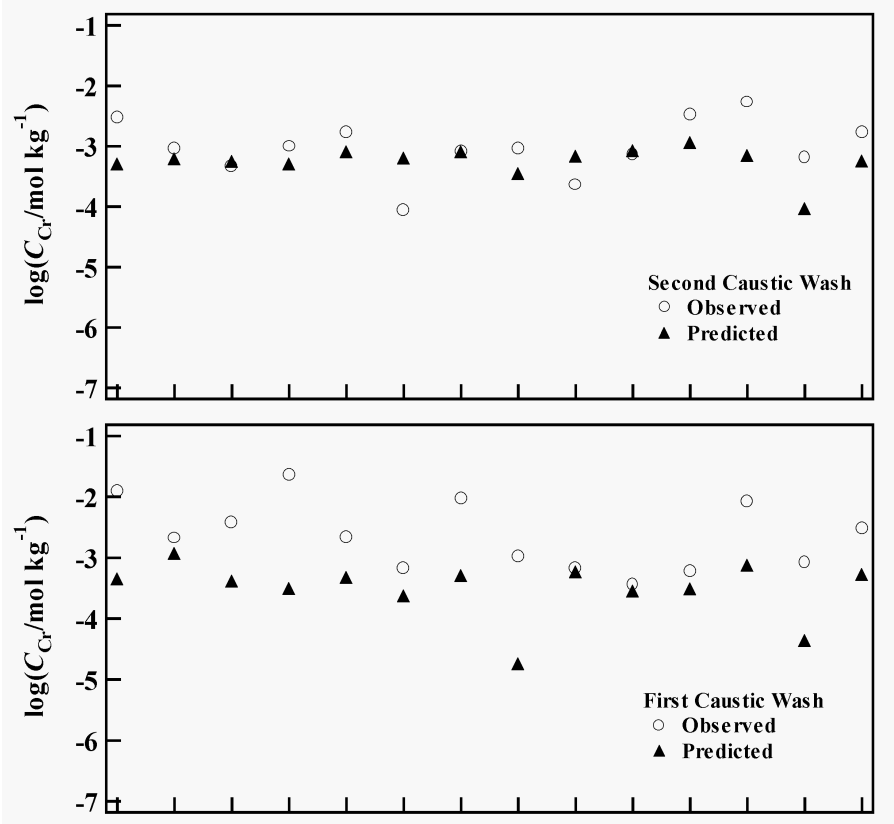

Figure 11. Predicted and observed chromium concentrations in sludge leachates (points on $\mathrm{X}$ axis from left to right represent Hanford tanks S101, S104, S107, S111, BY104, BY108, BY110, T104, C107, BX107, B111, T111, C103, and AN104). Electrolytes in leachates vary from a mixture containing sodium, aluminum, hydroxide, nitrate, nitrite, phosphate, carbonate, and sulfate in various proportions to primarily $\mathrm{NaOH}$ [see Rai et al. 2002 for details]. 


\section{LITERATURE CITED}

Finholt, J. E., M. E. Thompson, R. E. Connick. 1981. Hydrolytic Polymerization of Chromium(III). 2. A trimeric species. Inorg. Chem. 20:4151-4155.

Friese, J. I., B. Ritherdon, S. B. Clark, L. Rao, and Z. Zhang. 2004. Oxidation of Cr(III) oligomers by persulfate under alkaline conditions. (Manuscript in preparation)

Friese, J. I., B. Ritherdon, S. B. Clark, Z. Zhang, L. Rao, and Dhanpat Rai. 2002. Chromatographic Separation and Characterization of Hydrolyzed Cr(III) Species. Analytical Chemistry 74:2977-2984.

Koltoff, I. M. and I. K. Miller. 1951. The Chemistry of Persulfate. I. The Kinetics and Mechanism of the Decomposition of the Persulfate Ion in Aqueous Medium. J. Am. Chem. Soc. 73:3055-3059.

Krot, N. N., F. P. Shilov, A. M. Fedoseev, N. A. Budantseva, M. V. Nikonov, MA. B. Yusov, A. Y.

Lumetta, G. J., B. M. Rapko, M. J. Wagner, J. Liu, and Y. L. Chen. 1996a. Washing and Caustic

Leaching of Hanford Tank Sludges: Results of FY 1996 Studies. PNNL-11278, Rev.1. Pacific Northwest National Laboratory, Richland, Washinton, USA.

Lumetta, G. J., I. E. Burgeson, M. J. Wagner, J. Liu, and Y. L. Chen. 1997. Washing and Caustic Leaching of Hanford Tank Sludge: Results of FY 1997 Studies. PNNL-11636. Pacific Northwest National Laboratory, Richland, Washington, USA.

Pitzer, K. S. 1991. Activity Coefficients in Electrolyte Solutions. 2nd Ed., CRC Press, Inc., Boca Raton.

Pitzer, K. S. and L. F. Silvester. 1976. Thermodynamics of Electrolytes. VI. Weak Electrolytes Including $\mathrm{H}_{3} \mathrm{PO}_{4}$. J. Solution. Chem. 5:269.

Rai, D., N. J. Hess, L. Rao, Z. Zhang, A. R. Felmy, D. A. Moore, S. B. Clark, and G. J. Lumetta. 2002. Thermodynamic Model for the Solubility of $\mathrm{Cr}(\mathrm{OH})_{3}(\mathrm{am})$ in Concentrated $\mathrm{NaOH}$ and $\mathrm{NaOH}-\mathrm{NaNO}_{3}$ Solutions. Journal of Solution Chemistry 31:343-367.

Rai, Dhanpat, D. A. Moore, N. J. Hess, L. Rao, S. B. Clark. 2004. Chromium(III) Hydroxide Solubility in the Aqueous $\mathrm{Na}^{+}-\mathrm{OH}^{-}-\mathrm{H}_{2} \mathrm{PO}_{4}{ }^{-}-\mathrm{HPO}_{4}{ }^{2-}-\mathrm{PO}_{4}{ }^{3-}-\mathrm{H}_{2} \mathrm{O}$ System: A Thermodynamic Model. Journal of Solution Chemistry (in press).

Rai, D., B. M. Sass, and D. A. Moore. 1987. Cr(III) Hydrolysis Constants and Solubility of Cr(III) Hydroxide. Inorg. Chem. 26:345-349.

Rao, L., Z. Zhang, J. I Friese,., B. Ritherdon, S. B. Clark, N. J. Hess, and D. Rai. 2002. Oligomerization of chromium(III) and its impact on the oxidation of chromium(III) by hydrogen peroxide in alkaline solutions. J. Chem. Soc., Dalton Trans. 2:267-274.

Rapko, B. M., G. J. Lumetta, and M. J. Wagner. 1995. Washing and Caustic Leaching of Hanford Tank Sludges: Results of FY 1995 Studies. PNNL-10712. Pacific Northwest National Laboratory, Richland, Washington, USA.

Spiccia, L., H. Stoeckli-Evans, W. Marty, and R. Giovanoli. 1987. A New "Active" Chromium (III) Hydroxide. Inorg. Chem. 26:474. 


\section{PLANNED ACTIVITIES}

While the studies conducted under our current EMSP project have provided extensive validated fundamental data for aqueous species as well as results of practical importance on the solubility of $\mathrm{Cr}(\mathrm{OH})_{3}(\mathrm{am})$ and its redox reactivity, they have also pointed out that the extent of $\mathrm{Cr}$ leaching in caustic wash, which is being proposed as one of the treatments, and in oxidative dissolution is highly dependent on the nature of the $\mathrm{Cr}$ (III) solid phases and aqueous species. Out of a large number of $\mathrm{Cr}$ (III)-solid phases [e.g., $\mathrm{Cr}(\mathrm{OH})_{3}(\mathrm{am}), \mathrm{CrO}(\mathrm{OH}),(\mathrm{Fe}, \mathrm{Cr})(\mathrm{OH})_{3}(\mathrm{am}), \mathrm{Fe}(\mathrm{Cr}, \mathrm{Fe})_{2} \mathrm{O}_{4}, \mathrm{FeCr}_{2} \mathrm{O}_{4}, \mathrm{Al} / \mathrm{Cr}(\mathrm{OH})_{3}(\mathrm{am})$ ] that have been identified in tank sludges, $\mathrm{Cr}(\mathrm{OH})_{3}(\mathrm{am})$ is the most soluble, and other solid phases are expected to have solubilities of many orders of magnitude lower. While caustic wash dissolves a reasonable amount of $\mathrm{Cr}(\mathrm{OH})_{3}(\mathrm{am})$, it will not be effective with solid phases that have solubilities orders of magnitude lower. Fundamental information about the formation, stability, and oxidative dissolution of these other solid phases is not available and is required to develop effective pretreatment processes to remove $\mathrm{Cr}$ from sludges. Developing these fundamental data is the objective of the ongoing research.

\section{INFORMATION ACCESS (scientific communications prepared as part of this project)}

\section{Journal Articles}

Rai, Dhanpat, D. A. Moore, N. J. Hess, L. Rao, S. B. Clark. 2004. Chromium(III) Hydroxide Solubility in the Aqueous $\mathrm{Na}^{+}-\mathrm{OH}^{-}-\mathrm{H}_{2} \mathrm{PO}_{4}^{-}-\mathrm{HPO}_{4}{ }^{2-}-\mathrm{PO}_{4}{ }^{3-}-\mathrm{H}_{2} \mathrm{O}$ System: A Thermodynamic Model. Journal of Solution Chemistry (in press).

Zhang, Z., L. Rao, Dhanpat Rai, S. B. Clark. 2004. Characterization of Chromium(III) Hydroxide Solids and Their Oxidation by Hydrogen Peroxide. Materials Research Society Symposium Proceedings (in press).

J. I. Friese, B. Ritherdon, S. B. Clark, L. Rao, and Z. Zhang. 2004. Oxidation of Cr(III) oligomers by persulfate under alkaline conditions. (Manuscript in preparation)

Friese, J. I., B. Ritherdon, S. B. Clark, Z. Zhang, L. Rao, and Dhanpat Rai. 2002. Chromatographic Separation and Characterization of Hydrolyzed Cr(III) Species. Analytical Chemistry 74: 2977 - 2984.

Rai, Dhanpat, N. J. Hess, L. Rao, Z. Zhang, A. R. Felmy, D. A. Moore, S. B. Clark, G. J. Lumetta. 2002. Thermodynamic Model for the Solubility of $\mathrm{Cr}(\mathrm{OH})_{3}(\mathrm{am})$ in Concentrated $\mathrm{NaOH}$ and $\mathrm{NaOH}-\mathrm{NaNO}_{3}$ Solutions. Journal of Solution Chemistry 31: 343-367.

Rao, L., Z. Zhang, J. I Friese,., B. Ritherdon, S. B. Clark, N. J. Hess, and Dhanpat Rai. 2002. Oligomerization of chromium(III) and its impact on the oxidation of chromium(III) by hydrogen peroxide in alkaline solutions. J.Chem.Soc., Dalton Trans. 2002(2): 267 - 274. 


\section{Technical Reports}

Rai, Dhanpat, L. Rao, and S. B. Clark. 2003. Speciation, Dissolution, and Redox Reactions of Chromium Relevant to Pretreatment and Separation of High-Level Tank Wastes. FWP 42380. U. S. Department of Energy, Richland Operations Office.

Rai, Dhanpat, L. Rao, and S. B. Clark. 2002. Speciation, Dissolution, and Redox Reactions of Chromium Relevant to Pretreatment and Separation of High-Level Tank Wastes. In: Science to Support DOE Site Cleanup: The Pacific Nothwest National Laboratory Environmental Management Science Program Awards. PNNL-13928, Pacific Northwest National Laboratory, Richland, WA, PP. 1.39 - 1.51.

Rai, D., L. Rao, S. B. Clark, N. J. Hess, and G. J. Lumetta. 2000. Speciation, Dissolution, and Redox Reactions of Chromium Relevant to Pretreatment and Separation of High-Level Tank Wastes. In: Science to Support DOE Site Cleanup: The Pacific Northwest National Laboratory Science Program Awards. PNNL- 13262, Pacific Northwest National Laboratory, Richland, WA, pp. 1.15-1.17

Rai, D., L. Rao, S. B. Clark, and N. J. Hess. March 2000. Speciation, Dissolution, and Redox Reactions of Chromium Relevant to Pretreatment and Separation of High-Level Tank Wastes. Project Summary submitted to EMSP.

Rai, D., L. Rao, S. B. Clark, N. J. Hess, and G. J. Lumetta. 1999. Speciation, Dissolution, and Redox Reactions of Chromium Relevant to Pretreatment and Separation of High-Level Tank Wastes. In: Science to Support DOE Site Cleanup: The Pacific Northwest National Laboratory Science Program Awards. PNNL- 12208, Pacific Northwest National Laboratory, Richland, WA, pp. 1.61-1.86

\section{Presentations}

Rai, D., L Rao, and SB Clark, N. J. Hess. 2003. Speciation, Dissolution, and Redox Reactions of Chromium Relevant to Pretreatment and Separation of High-Level Tank Wastes" as a part of a symposium on nuclear waste management. $226^{\text {th }}$ American Chemical Society national meeting, September 7-11, 2003, New York City.

Rai, D., L Rao, and SB Clark, N. J. Hess. 2001. Speciation, Dissolution, and Redox Reactions of Chromium Relevant to Pretreatment and Separation of High-Level Tank Wastes (11/08/2001) at National DOE/EMSP Workshop, Richland WA.

Rao, L., D. Rai, S. B. Clark, Z. Zhang, N. J. Hess, B. Ritherdon, and J. Friese. 2000. Dissolution of $\mathrm{Cr}(\mathrm{OH})_{3}(\mathrm{am}) / \mathrm{Cr}_{2} \mathrm{O}_{3}$ (c) and Oxidation of $\mathrm{Cr}(\mathrm{III})$ in Alkaline Solutions. A presentation at the 219th ACS National Meeting, San Francisco, California, March 2000.

Friese, J., B. Ritherdon, O. Gerasimov, S. Lymar, J. Hurst, Z. Zhang, L. Rao, D. Rai, and S. B. Clark. 2000. Oxidation of Trivalent Cr Using Oxidants Relevant to High-Level Radioactive Waste. A presentation at the 219th ACS National Meeting, San Francisco, California, March 2000. 
Rai, D., L. Rao, S. B. Clark, N. J. Hess, and A. R. Felmy. 2000. Solubility of Cr(III) Compounds and Their Redox Transformation Reactions: Application to Pretreatment of High-Level Waste Sludges. An oral presentation at the EMSP workshop, Atlanta, Georgia, April 2000.

Rai, D., L. Rao, S. B. Clark, N. J. Hess, and A. R. Felmy. 2000. Speciation, Dissolution, and Redox Reactions of Chromium Relevant to Pretreatment and Separation of High-Level Tank Wastes. Poster presentation at the EMSP workshop, Atlanta, Georgia, April 2000.

Friese, J., B. Ritherdon, S. B. Clark, L. Rao, and Z. Zhang. 2000. Removing Chromium from High-Level Radioactive Waste Streams: Speciation and Reactivity of Cr(III) Oligomers Under Highly Alkaline Conditions. A presentation at the 221th ACS National Meeting, San Diego, California, April 2001.

Rao, L., D. Rai, S. B. Clark, A. R. Felmy, N. J. Hess, Z. Zhang, and B. Ritherdon. 1999. Speciation, Dissolution, and Redox Reactions of Cr(III) in Alkaline Solutions. A presentation at the 218th ACS National Meeting, New Orleans, Louisiana, August 1999. 